\title{
Corrole NH Tautomers: Spectral Features and Individual Protonation
}

Yulia B. Ivanova, ${ }^{\dagger}$ Vadim A. Savva, ${ }^{\ddagger}$ Nugzar Z. Mamardashvili, ${ }^{\dagger}$ Aleksander S. Starukhin, ${ }^{\ddagger}$ Thien H. Ngo, ${ }^{\S} \|$ Wim Dehaen, ${ }^{\S}$ Wouter Maes, ${ }^{*},, \perp$ and Mikalai M. Kruk*, ${ }^{*}$

\footnotetext{
${ }^{\dagger}$ Institute of Solution Chemistry of Russian Academy of Sciences, 153045, Ivanovo, Academicheskaya str. 1, Russian Federation

${ }^{\ddagger}$ B. I. Stepanov Institute of Physics of National Academy of Sciences, Pr. Nezavisimosti 68, Minsk 220072, Belarus

${ }^{\S}$ Molecular Design and Synthesis, Department of Chemistry, KU Leuven, Celestijnenlaan 200F, B-3001 Leuven, Belgium

"Institut für Chemie und Biochemie-Organische Chemie, Freie Universität Berlin, Takustrasse 3, D-14195 Berlin, Germany

${ }^{\perp}$ Design \& Synthesis of Organic Semiconductors (DSOS), Institute for Materials Research (IMO-IMOMEC), Hasselt University, Universitaire Campus, Agoralaan 1, Building D, B-3590 Diepenbeek, Belgium
}

\begin{abstract}
Protonation of a free-base meso-pyrimidinyl-substituted $\mathrm{AB}_{2}$ corrole $\left(\mathrm{H}_{3} \mathrm{AB}_{2}\right)$ in ethanol solution by stepwise addition of sulfuric acid has been studied in the temperature range from 293 to $333 \mathrm{~K}$. The formation rate of protonated species was found to depend profoundly on the temperature at which the titration was undertaken. Two steps in the titration curve were identified at temperatures around 293-298 K, whereas one-step formation of protonated species was found to occur at temperatures above $308 \mathrm{~K}$. The protonation product was the same in both cases, i.e., $\mathrm{H}_{4} \mathrm{AB}_{2}^{+}$corrole, protonated at the macrocycle core nitrogen atoms. The two steps in the protonation kinetics at lower temperatures were attributed to protonation of individual tautomers of the free-base $\mathrm{H}_{3} \mathrm{AB}_{2}$ corrole. To the best of our knowledge, this is the first well-illustrated (spectrophotometric) observation of individual properties of corrole $\mathrm{NH}$ tautomers in fluid solution. Concomitant

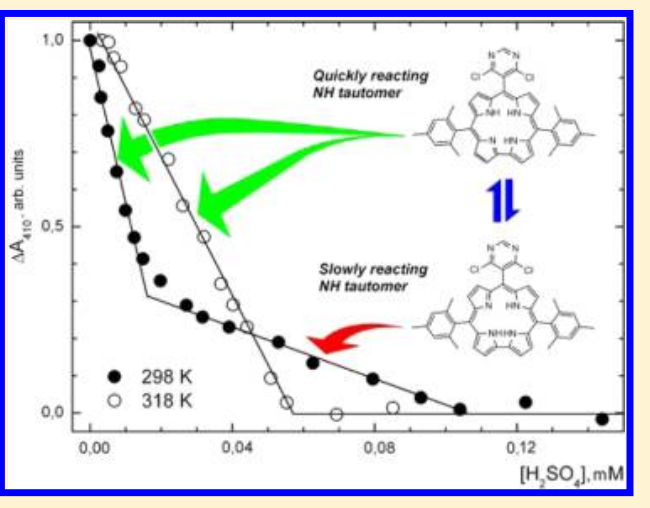
increase in the $\mathrm{NH}$ tautomerization rate with increasing temperature is proposed to account for the one-step protonation. Evidences for the role of individual corrole NH tautomers in the protonation process as well as their optical features are discussed based on spectroscopic results and simulation data.
\end{abstract}

\section{INTRODUCTION}

Corroles, contracted tetrapyrrolic macrocycles lacking one meso-carbon atom, have emerged as attractive porphyrinoid materials, notably during the past decade, in which novel synthetic pathways toward meso-triaryl-substituted corroles and numerous postmacrocyclization functionalization protocols have considerably enlarged the set of available corrole structures and their potential applications. ${ }^{1,2}$ Corrole-based materials are nowadays extensively studied as novel catalysts, antitumor treatment, and imaging agents as well as active materials in the design of new sensors and optoelectronic devices. $^{3,4}$

Two major structural peculiarities of corroles relative to porphyrins are the presence of three rather than two $\mathrm{NH}$ protons in the coordination core and their lower symmetry. The phenomenon of $\mathrm{NH}$ tautomerization has been known for a long time for free-base $(\mathrm{Fb})$ porphyrins and has been studied in detail by NMR and optical spectroscopy methods in both the liquid and solid states. ${ }^{5}$ The presence of three $\mathrm{NH}$ protons in the corrole macrocyclic core and the inherent asymmetry impose many questions concerning the specific details of the corrole tautomerization mechanism. Quantum chemical calculations predict a substantially lower barrier for corrole tautomerization $\left(2.45 \mathrm{kcal} \mathrm{mol}^{-1}\right)^{6}$ as compared to that of porphyrins $\left(17 \mathrm{kcal} \mathrm{mol}^{-1}\right){ }^{7}$ which leads to a much faster rate of proton migration in the tetrapyrrolic core. The lower symmetry of the $\mathrm{Fb}$ corrole macrocycle $\left(C_{\mathrm{s}}\right)$ compared to that of a $\mathrm{Fb}$ porphyrin $\left(D_{2 h}\right)$ implies that the two tautomeric forms are distinct and structurally quite different (see Scheme 1),

Scheme 1. Equilibrium Showing Two Corrole NH Tautomers

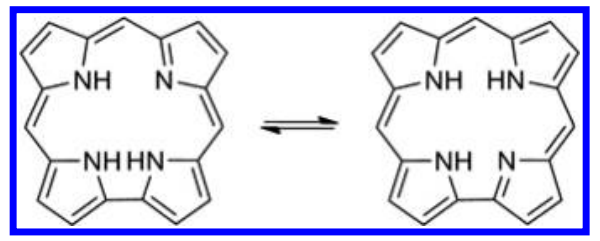

which opens the possibility to detect the two $\mathrm{NH}$ tautomers for any corrole derivative, independently of the peripheral substitution pattern and even in fluid solutions at room temperature, in contrast to porphyrins where $\mathrm{NH}$ tautomers of symmetrically substituted derivatives have been indistinguishable. Thus, any change in the equilibrium between the two

Received: May 31, 2012

Revised: September 10, 2012

Published: September 17, 2012 
corrole $\mathrm{NH}$ tautomers may contribute to the pattern of the ground state absorption spectra as well as to the solvent dependent spectral features of corroles in general. ${ }^{8}$

Another distinct feature of corroles is their unusually high $\mathrm{NH}$ acidity relative to porphyrins and all other related macrocycles, which holds for both pyrrole-alkylated and meso-substituted derivatives. ${ }^{9}$ It was suggested that a possible explanation of such a difference in acid-base equilibria between corroles and porphyrins is the number of $\mathrm{NH}$ protons in each state. $^{9 \mathrm{c}}$ The proposed hypothesis implies that a monoprotonated corrole should be considered as a species corresponding to a diprotonated porphyrin, while the neutral $\mathrm{Fb}$ corrole corresponds to a monoprotonated porphyrin. A number of studies on the acid-base equilibria in corroles have been performed to date, both in aqueous and nonaqueous solvents. ${ }^{9,10}$ It was found that the $\mathrm{p} K_{\mathrm{a}}$ value for the core nitrogen protonation, with formation of monoprotonated $\mathrm{H}_{4} \mathrm{Cor}^{+}$species, is determined by both the relative basicity of the solvent and the corrole, and the latter can be tuned by substitution with electron-donating or electron-withdrawing groups at the meso- or $\beta$-pyrrolic positions of the corrole macrocycle. ${ }^{9 c, 10} \mathrm{UV}$-visible absorption spectra of monoprotonated $\mathrm{H}_{4} \mathrm{Cor}^{+}$species show a strong pure electronic $\mathrm{Q}(0-0)$ band, whereas in spectra of $\mathrm{Fb}$ corroles $\mathrm{H}_{3}$ Cor, the vibronic $\mathrm{Q}(0-1)$ bands dominate in the visible range of the spectrum. The protonation of peripheral substituents of corroles has also been observed in addition to protonation of the core nitrogen atoms. Depending on the number of meso-pyridyl substituents, which were able to be protonated, double or triple positively charged species were formed at the end of the titration. ${ }^{10 \mathrm{~b}} \mathrm{It}$ should be stressed that pyridyl substituents are more basic than the core nitrogen atoms and undergo protonation first, so the core nitrogen protonation occurred for the species already bearing a positive charge. However, the electronic absorption spectra for all of these core-protonated corroles were found to keep near resemblance, regardless of the different total charge of the species.

One of the groups involved in this work has developed specific synthetic aspects of meso-pyrimidinylporphyrinoids, $={ }^{11}$ and meso-pyrimidinylcorroles, in particular, ${ }^{12}$ with varying substitution patterns. Three families of meso-pyrimidinylsubstituted $\mathrm{AB}_{2^{-}}, \mathrm{A}_{2} \mathrm{~B}$-, and $\mathrm{A}_{3}$-corroles have been prepared ( $A=4,6$-dichloropyrimidin-5-yl). Extensive results on the synthesis and functionalization, structural elucidation, spectral features, and photophysical properties have recently been reported for these contracted porphyrinoids. ${ }^{12}$ It was demonstrated that pyrimidinylcorroles represent attractive scaffolds toward innovative corrole materials. The broad scope of (postmacrocyclization) substitution possibilities of the pyrimidinylcorrole macrocycle, as demonstrated by nucleophilic/electrophilic aromatic substitution $\left(S_{N} A r / S_{E} A r\right)$ and Pd-catalyzed cross-coupling reactions, allows facile and efficient access to a diversity of functional corrole derivatives. ${ }^{12 c}$ A result with particular interest for the design of corrole compounds with high yielding triplet state formation is that ortho-chlorine groups on the meso-pyrimidinyl substituents are able to increase the intersystem crossing rate constant dramatically by means of the internal heavy-atom effect. ${ }^{12 \mathrm{e}}$

Electronic communication between the meso-pyrimidinyl groups and the corrole macrocycle is considered to be a tool for fine-tuning of the macrocycle's basicity-acidity equilibrium. However, there were no studies in this field to date. In this article, we have started to explore the acid-base equilibria of meso-pyrimidinylcorroles. Results on the spectrophotometric titration of 10-(4,6-dichloropyrimidin-5-yl)-5,15-dimesitylcorrole $\left(\mathrm{H}_{3} \mathrm{AB}_{2}\right)$ with sulfuric acid in ethanol solution are presented, and the influence of the temperature on the protonation rate is discussed. Special attention is devoted to the role of individual corrole $\mathrm{NH}$ tautomers in the formation of the protonated meso-pyrimidinyl-substituted $\mathrm{AB}_{2}$-corrole $\left(\mathrm{H}_{4} \mathrm{AB}_{2}^{+}\right)$.

\section{EXPERIMENTAL AND THEORETICAL METHODS}

10-(4,6-Dichloropyrimidin-5-yl)-5,15-dimesitylcorrole $\left(\mathrm{H}_{3} \mathrm{AB}_{2}\right)$ was prepared in accordance with a previously published synthetic procedure. ${ }^{12 a, c}$ Ground state absorption spectra in the temperature range 293-333 K were measured with a UVvis spectrophotometer PB 2201 (JSC “Solar”, Belarus) equipped with a temperature-controlled cell. Corrole concentrations in ethanol solutions were measured spectrophotometrically by means of preliminarily determined extinction coefficients at $298 \mathrm{~K}:\left(\lambda_{\max }(\mathrm{EtOH}) / \mathrm{nm} 410\left(\log \varepsilon / \mathrm{dm}^{3} \mathrm{~mol}^{-1}\right.\right.$ $\mathrm{cm}^{-1}$ 5.02), 427 (4.92), 570 (4.30), 599 (4.05), and 635 (3.28) for $\mathrm{H}_{3} \mathrm{AB}_{2}$ and 421 (5.07), 533 (3.77), 597 (3.87), and 644 (4.56) for $\mathrm{H}_{4} \mathrm{AB}_{2}^{+}$. No sign of aggregation was found for a corrole concentration range up to $6 \cdot 0.10^{-5} \mathrm{M}$, wherein all experiments have been carried out.

Spectrophotometric titrations were performed with a Varian Cary 100 spectrophotometer. A temperature-controlled quartz cell was charged with $50 \mathrm{~mL}$ of a $1.5 \cdot 10^{-5} \mathrm{M}$ solution of the $\mathrm{Fb}$ corrole $\mathrm{H}_{3} \mathrm{AB}_{2}$ in ethanol. A solution of sulfuric acid in ethanol $(0.01 \mathrm{M})$ was used as the titrant. The titrant concentration was chosen so that the total volume change of the solution by the end of the titration procedure did not exceed $1 \%$. The solution dilution was taken into account by following eq 1 :

$$
A_{\mathrm{T}}=\frac{A_{\mathrm{T}}^{0}}{1+\frac{\sum V}{V_{0}}}
$$

with $A_{\mathrm{T}}$ the current optical density, $A_{\mathrm{T}}^{0}$ the initial value of the optical density before adding the titrant, $\Sigma V$ the total volume of the titrant added, and $V_{0}$ the initial volume of the corrole solution. The choice for ethanol as the solvent for the titration was based on the fact that it is inert toward tetrapyrrolic macrocycles and exhibits the properties of a weak acid and a weak base simultaneously. The ethanol-sulfuric acid system has been studied very well in the range of acid concentrations from 0.01 to $11.22 \mathrm{M}^{13}$ The dependence of the Hammett constant $H_{0}$, i.e., the acidity function characterizing the proton donating power of the medium, on the sulfuric acid concentration in an ethanol-sulfuric acid system is described by eq 2 :

$$
H_{0}=\frac{2.0482+0.7776 C}{1+8.7975 C-0.2413 C^{2}}
$$

where the sulfuric acid concentration $C$ is in $M$. The dependence of $\log \left(\mathrm{C}_{\mathrm{HL}}{ }^{+} / \mathrm{C}_{\mathrm{L}}\right)$ on $\mathrm{H}_{0}$ is a straight line with a slope close to unity, indicating that the acid activity remains constant in the whole acid concentration range.

The solvents used were purified with standard procedures. ${ }^{14}$ The pyrimidinylcorrole was purified by column chromatography (silica) prior to use. ${ }^{12 a}$ All experiments were carried out with freshly prepared solutions to minimize degradation of the corrole species upon prolonged exposure to light and air. Equilibrium constants $K_{\mathrm{b}}$ were calculated according to standard 


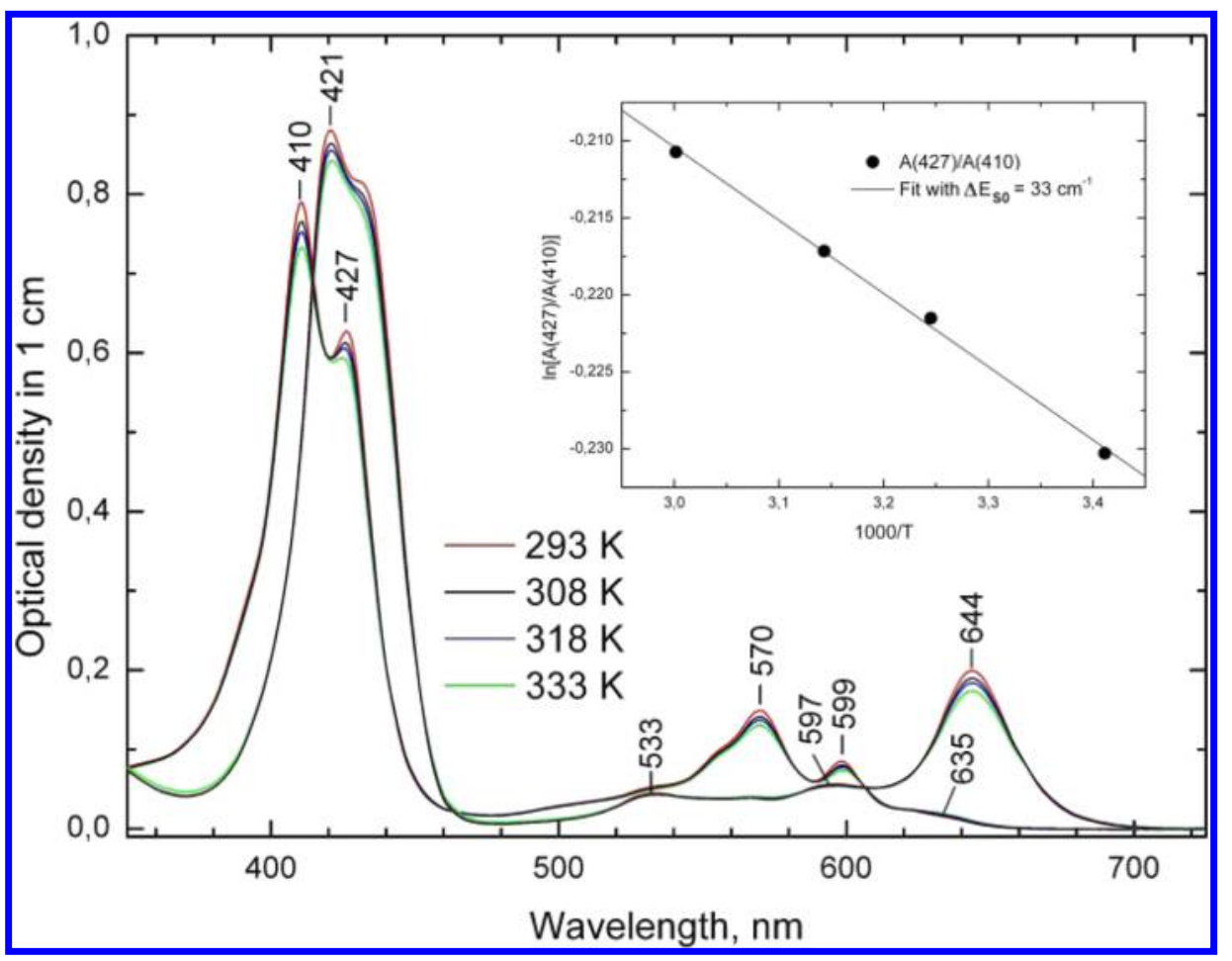

Figure 1. Ground state absorption spectra of $\mathrm{Fb}$ meso-pyrimidinyl-corrole $\mathrm{H}_{3} \mathrm{AB}_{2}\left(\lambda_{\max }=410,427,570,599\right.$, and $\left.635 \mathrm{~nm}\right)$ and its monoprotonated form $\mathrm{H}_{4} \mathrm{AB}_{2}^{+}\left(\lambda_{\max }=421,533,597\right.$, and $\left.644 \mathrm{~nm}\right)$ in equimolar concentrations $\left(7.5 \times 10^{-6} \mathrm{M}\right)$ at different temperatures. The inset shows the van't Hoff plot for the equilibrium of the two NH tautomers (see text).

procedures. $^{15}$ The uncertainty in the determination was not higher than $\pm 5 \%$.

\section{RESULTS AND DISCUSSION}

Ground state absorption spectra for equimolar concentrations of the $\mathrm{Fb}$ meso-pyrimidinylcorrole $\left(\mathrm{H}_{3} \mathrm{AB}_{2}\right)$ and its protonated counterpart $\left(\mathrm{H}_{4} \mathrm{AB}_{2}^{+}\right)$in the temperature range $293-333 \mathrm{~K}$ are shown in Figure 1. There are no changes in the equilibrium between the $\mathrm{Fb}$ and monoprotonated species in the whole temperature range studied. Thus, the isosbestic points hold their positions at 415,464 , and $606 \mathrm{~nm}$, indicating that the same equilibrium is involved in all cases. The maxima of the absorption bands remain also unchanged. Slight decreases in the absorbance of the solutions upon going from 293 to $333 \mathrm{~K}$ are due to thermal volume expansion leading to an apparent concentration decrease. This phenomenon accounts for all the optical density changes observed for protonated $\mathrm{H}_{4} \mathrm{AB}_{2}{ }^{+}$ molecules. In the case of the $\mathrm{Fb}$ corrole molecules, one more factor seems to influence the absorbance changes. Indeed, for the long wavelength absorption band centered at $635 \mathrm{~nm}$, the optical density remains about the same, whereas for all other bands, the optical density value decreases. This fact points to an increase in the absorptivity of this band. Comparison of the peak intensities of the bands centered at 427 and $410 \mathrm{~nm}$ upon increasing temperature indicates that the absorptivity of both bands becomes slightly lower but with a different rate. The band centered at $427 \mathrm{~nm}$ decreases less than can be expected taking into account the decrease in ethanol density with rising temperature, whereas the band centered at $410 \mathrm{~nm}$ decreases more.

The analysis of the temperature behavior of these two bands has been carried out with a van't Hoff plot (Figure 1, inset). The analyzed value was taken as the ratio of the optical densities at the two wavelengths $\mathrm{A}_{427} / \mathrm{A}_{410}$, which, in fact, is proportional to the ratio of the $\mathrm{T} 1 \rightarrow \mathrm{T} 2$ and $\mathrm{T} 2 \rightarrow \mathrm{T} 1$ equilibrium constants for $\mathrm{NH}$ tautomerization. The energy difference $E_{\mathrm{S} 0}=33 \mathrm{~cm}^{-1}$ between the electronic ground states of the two $\mathrm{NH}$ tautomers was determined from the slope of the linear dependence. The population ratio of the two corrole $\mathrm{NH}$ tautomers changes with temperature, and the tautomer with higher ground state energy was found to be slightly more populated when the temperature was going from 293 to $333 \mathrm{~K}$. The two above facts should be considered as evidence for the heterogeneity of the $\mathrm{Fb}$ corrole species in solution at room temperature. ${ }^{16}$ The possible contribution to the measured temperature dependence of absorption from vibrationally hot ground states can be ruled out since, in that case, all the bands in the absorption spectrum would decrease in the same way. ${ }^{17}$ In the given case, it was observed (Figure 1, inset) that the bands exhibit a different temperature dependence.

Gouterman's four-orbital model for tetrapyrrolic compounds was shown to hold in the case of corrole macrocycles too. ${ }^{6,18}$ According to the four-orbital model, the absorbance in the visible and near-UV ranges is due to transitions between the two highest occupied (HOMOs) and the two lowest unoccupied molecular orbitals (LUMOs). ${ }^{19}$ The Soret band consists of two overlapping bands corresponding to two electronic transitions. In the case of the $\mathrm{Fb}$ porphyrins, it is known that the shape of the Soret band depends on the macrocycle's substitution pattern due to variations in the energy and oscillator strength of these two transitions. ${ }^{19 \mathrm{~b}}$ However, if two transitions belong to the same molecule, their temperature dependences should be identical. This is not the case for the $\mathrm{Fb}$ meso-pyrimidinylcorrole under consideration. Therefore, the two Soret transitions with maxima at 410 and $427 \mathrm{~nm}$ should be related with two types of molecules in solution. 


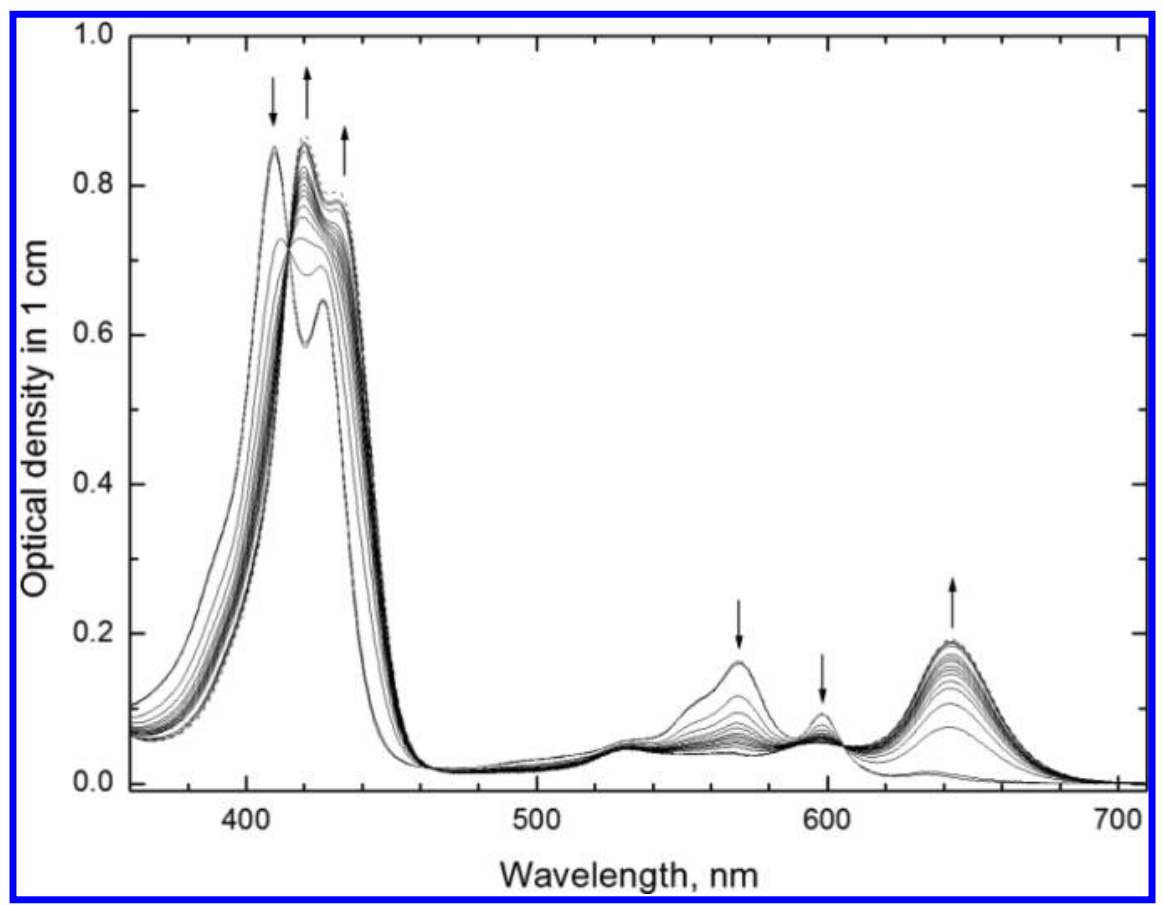

Figure 2. Changes in the ground state absorption spectra upon protonation of $\mathrm{Fb}$ meso-pyrimidinylcorrole $\mathrm{H}_{3} \mathrm{AB}_{2}\left(\mathrm{C}=7.5 \times 10^{-6} \mathrm{M}\right)$ at $293 \mathrm{~K}$ (sulfuric acid concentration range: $C_{\text {acid }}=0-1.05 \times 10^{-4} \mathrm{M}$ ). Arrows show the direction of spectral changes.

The presence of (significant amounts of) impurities seems unlikely due to the purification procedures applied during the course of the corrole preparation and the use of freshly prepared solutions (see experimental details). ${ }^{12 a, c}$ For a given $\mathrm{NH}$ tautomer, the twists of the aryl rings are the sole source of conformational heterogeneity. In the case under consideration (i.e., the $\mathrm{AB}_{2}$-meso-pyrimidinylcorrole $\mathrm{H}_{3} \mathrm{AB}_{2}$ ), all ortho-aryl positions are substituted with relatively bulky groups $(\mathrm{Cl}$ and $\mathrm{Me}$ ), so the degree of freedom for twisting is rather limited. The rotation of the aryl moieties over a relatively narrow range is most likely barely affecting the macrocycle's molecular orbitals (as can be concluded based on the available data for tetra-aryl-substituted porphyrins ${ }^{20}$ ). In addition, the narrow temperature range used (within $40^{\circ}$ ) cannot account for a substantial population redistribution between the possible conformers. The temperature dependence of the absorption spectrum of the protonated corrole $\mathrm{H}_{4} \mathrm{AB}_{2}{ }^{+}$, measured in a larger temperature range, can be fully explained with thermal volume expansion of the solvent (temperature-dependent solvent density change), and no sign of possible redistribution between the corrole conformers could be seen. Thus, the possible impact of conformational inhomogeneity on the measured spectra at different temperatures can be minimized.

As proposed above, the most probable origin of the heterogeneity in solution is the coexistence of two $\mathrm{NH}$ tautomers of the $\mathrm{Fb}$ corrole $\mathrm{H}_{3} \mathrm{AB}_{2}$. When two $\mathrm{NH}$ tautomers coexist in solution, four electronic transitions would overlap in the Soret band region. Indeed, the Soret band profile simulation with Gaussian type bands demonstrates that four peaks must be involved (at least) for satisfactory band profile fitting (not shown). Thus, expecting that the two most intense bands belong to different $\mathrm{NH}$ tautomers, the temperature dependence can be rationalized in terms of minor population redistribution between them with an increase in temperature. The small difference $\Delta E_{\mathrm{S} 0}$ implies that two tautomers seem to have comparable concentrations under the given conditions.
Therefore, the Soret band with a maximum at $427 \mathrm{~nm}$ can be tentatively assigned to the long wavelength tautomer $\mathrm{T} 1$, whereas the Soret band peaking at $410 \mathrm{~nm}$ belongs to the short wavelength tautomer $\mathrm{T} 2$. We like to stress here that there is no contradiction between the very close stability of the two corrole $\mathrm{NH}$ tautomer ground states (small $\Delta E_{\mathrm{S} 0}$ ) and the difference in the electronic structure of the two $\mathrm{NH}$ tautomers, which is expected to be distinct. ${ }^{6}$ Similar stability of the ground states does not necessarily imply a similar electronic structure. The excited states can be influenced much stronger than the ground states (tentatively, the LUMO seems to be more sensitive to the tautomerization state compared to the HOMO). Indeed, for the two corrole $\mathrm{NH}$ tautomers, the difference in the ground state energies is about $33 \mathrm{~cm}^{-1}$, but the energies of the first electronic transitions of the two $\mathrm{NH}$ tautomers differ for almost $1000 \mathrm{~cm}^{-1}$, as a result of a substantial difference in electronic structure. Similar results have very recently been reported by Nemykin et al., ${ }^{21}$ who stated that the difference in the ground state energies for two corrole $\mathrm{NH}$ tautomers seems to be small, but the difference in the transition energies for the Soret region amounts up to $\sim 1000 \mathrm{~cm}^{-1}$.

Soret band splitting in corroles and observation of two distinct transitions has been discussed previously. ${ }^{10 a, 12 c, 22,23}$ The splitting was first observed for meso-substitution with sterically demanding groups and was suggested to be an intrinsic property of sterically hindered meso-triarylcorroles. ${ }^{22,23}$ $\mathrm{A}_{2} \mathrm{~B}$-type corroles 5,15-bis(2,6-dichlorophenyl)-10-(4cyanophenyl)corrole and 5,15-dimesityl-10-(4-cyanophenyl)corrole showed Soret band splitting of the same order of magnitude: 891 and $1007 \mathrm{~cm}^{-1}$, respectively. ${ }^{10 a}$ This observation is in line with findings on an ortho effect in porphyrins, where 2,6-dichlorophenyl and 2,6-dimethylphenyl meso-substituents were found to have about the same effect. ${ }^{24}$ At the same time, an $\mathrm{A}_{2} \mathrm{~B}$-type corrole bearing two 4,6dichloropyrimidin-5-yl groups and the same B-group (i.e., 4cyanophenyl) shows no distinct splitting: the Soret band has a 


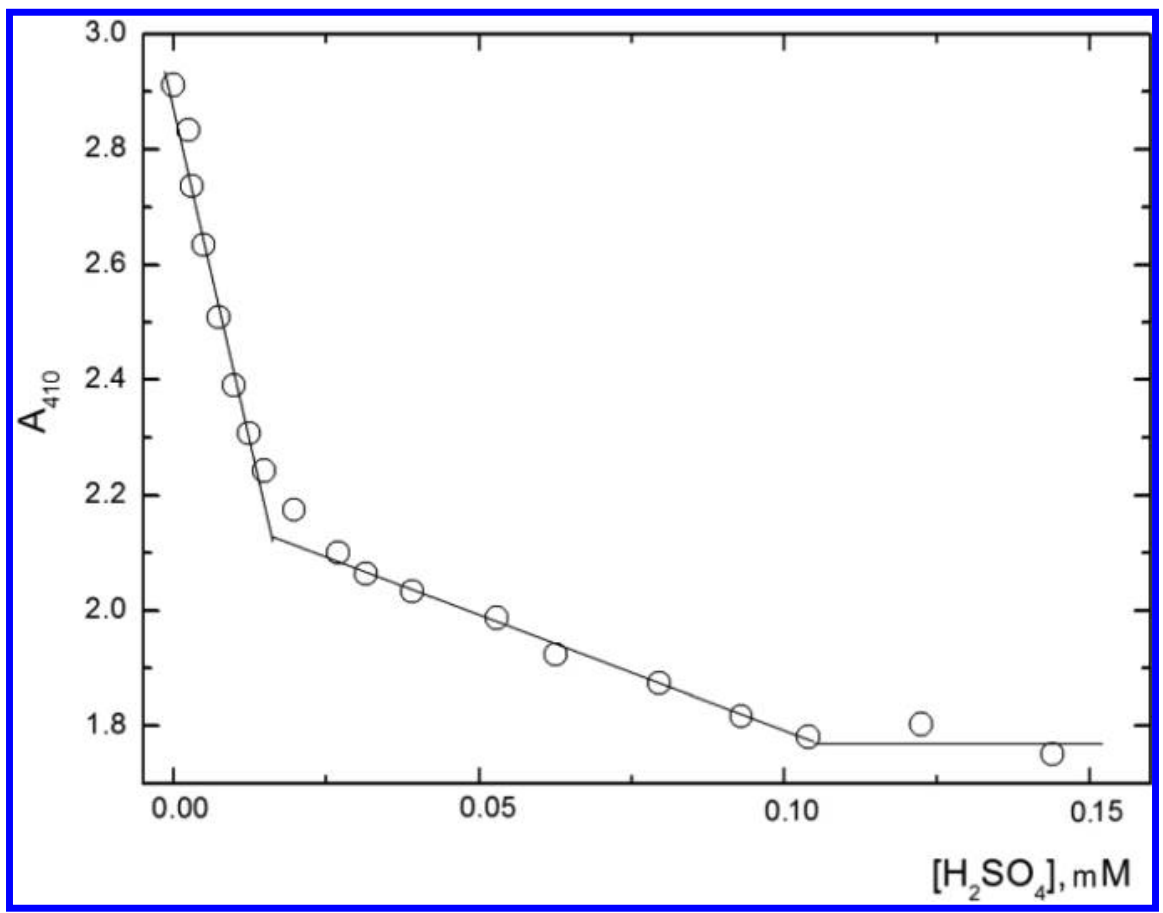

Figure 3. Titration curve for the protonation of $\mathrm{Fb}$ meso-pyrimidinyl-corrole $\mathrm{H}_{3} \mathrm{AB}_{2}\left(\mathrm{C}=3.3 \times 10^{-5} \mathrm{M}\right)$ at $\lambda=410 \mathrm{~nm}$ at $298 \mathrm{~K}$.

maximum at $416 \mathrm{~nm}$ and a weak shoulder at the long wavelength side due to the second electronic transition. ${ }^{12 \mathrm{e}}$ Moreover, in $\mathrm{AB}_{2}$-type 5,15-bis(2,6-dichlorophenyl)-10-(4,6dichloropyrimidin-5-yl)corrole, where two additional orthochlorine atoms appear, there was also no splitting observed. ${ }^{12 \mathrm{c}}$ Thus, one can conclude that steric hindrance (alone) cannot explain the splitting of the Soret band. We propose that the main contribution in Soret band splitting originates from the coexistence of two corrole NH tautomers, even in fluid solution at room temperature. The temperature dependence shown above, indicating that these two absorption bands belong to different species, provides strong support for this hypothesis. The value of the splitting between the two $\mathrm{NH}$ tautomers seems to be mostly due to electronic effects. For example, when comparing the two $\mathrm{AB}_{2}$-type corroles 5,15-bis(2,6-dichlorophenyl)-10-(4,6-dichloropyrimidin-5-yl)corrole and 5,15-dimesityl-10-(4,6-dichloropyrimidin-5-yl) corrole, ${ }^{12 \mathrm{c}}$ having about the same steric hindrance due to ortho effects, a rather small splitting was observed in the former case, resulting in a weak long wavelength shoulder on the main peak at $415 \mathrm{~nm}$, whereas in the latter case, two distinct bands with maxima at 412 and $428 \mathrm{~nm}$ were found, giving rise to a Soret band splitting of 907 $\mathrm{cm}^{-1}$.

Thus, all the arguments above support the assignment of the most intense bands in the Soret region, with maxima at 410 and $427 \mathrm{~nm}$, as belonging to the two individual $\mathrm{NH}$ tautomers of $\mathrm{Fb}$ corrole $\mathrm{H}_{3} \mathrm{AB}_{2}$. The following protonation studies and theoretical treatment of the titration curves provide additional evidence for this assignment. Moreover, a large set of spectroscopic data on the individual optical (fluorescence) properties of corrole $\mathrm{NH}$ tautomers in solution in a large temperature range, confirming this view, has also been reported in one companion article. ${ }^{25}$

The evolution of the ground state absorption spectra upon going from $\mathrm{Fb} \mathrm{H} \mathrm{H}_{3} \mathrm{AB}_{2}$ corrole to protonated $\mathrm{H}_{4} \mathrm{AB}_{2}{ }^{+}$corrole during titration with sulfuric acid at $293 \mathrm{~K}$ is shown in Figure 2. The same set of isosbestic points was observed over the course of the whole titration procedure, pointing out a single protonation equilibrium leading to formation of protonated $\mathrm{H}_{4} \mathrm{AB}_{2}{ }^{+}$corrole without any intermediate. The positions of the isosbestic points were the same as those measured above for the equimolar concentration of $\mathrm{Fb}$ and protonated corrole in a wide temperature range (see Figure 1). The titration was repeated at $298 \mathrm{~K}$ and has revealed essentially the same spectral evolution. Surprisingly, the corresponding titration curves (Figure 3 shows the one taken at $298 \mathrm{~K}$ ) demonstrate two distinct steps in the protonation kinetics. At low acid concentrations, the absorbance is going down very fast and it is slowing down at the final stages. About $70-80 \%$ of absorbance changes are observed within the first stage and the remainder occurs within the second one. Having determined the coordinates of the folding point in the titration curve using a known procedure, ${ }^{26}$ the two protonation steps were separated, and the corresponding protonation constants were calculated. The values of the protonation constants for the first $\left(K_{\mathrm{b} 1}\right)$ and second $\left(K_{\mathrm{b} 2}\right)$ steps were 151 and 41 , respectively, with corresponding $\log K$ values of 2.18 and 1.6.

The involvement of different protonation sites (corrole macrocycle vs meso-pyrimidinyl substituent), as was found for the meso-pyridyl-substituted corroles reported by Kadish et al., ${ }^{10 \mathrm{~b}}$ could be excluded in the case under consideration due to the clear spectral evidence of one single protonation product (as described above): exactly the same absorbance was observed for the protonated species, fitting well to the available spectra of the core-protonated forms for other triarylcorroles, ${ }^{10}$ at both the first and second protonation step, and the set of isosbestic points was identical as well. This is in contract with the case described by Kadish et al. ${ }^{10 b}$ in which the macrocycle core and the pyridyl substituents were protonated at clearly distinct protonation steps, and the spectra at the corresponding titration steps were drastically different. An additional important observation was that an increase in the number of pyridyl units ultimately led to an increase in the number of protonation steps. ${ }^{10 \mathrm{~b}}$ Preliminary data obtained by us for meso- 


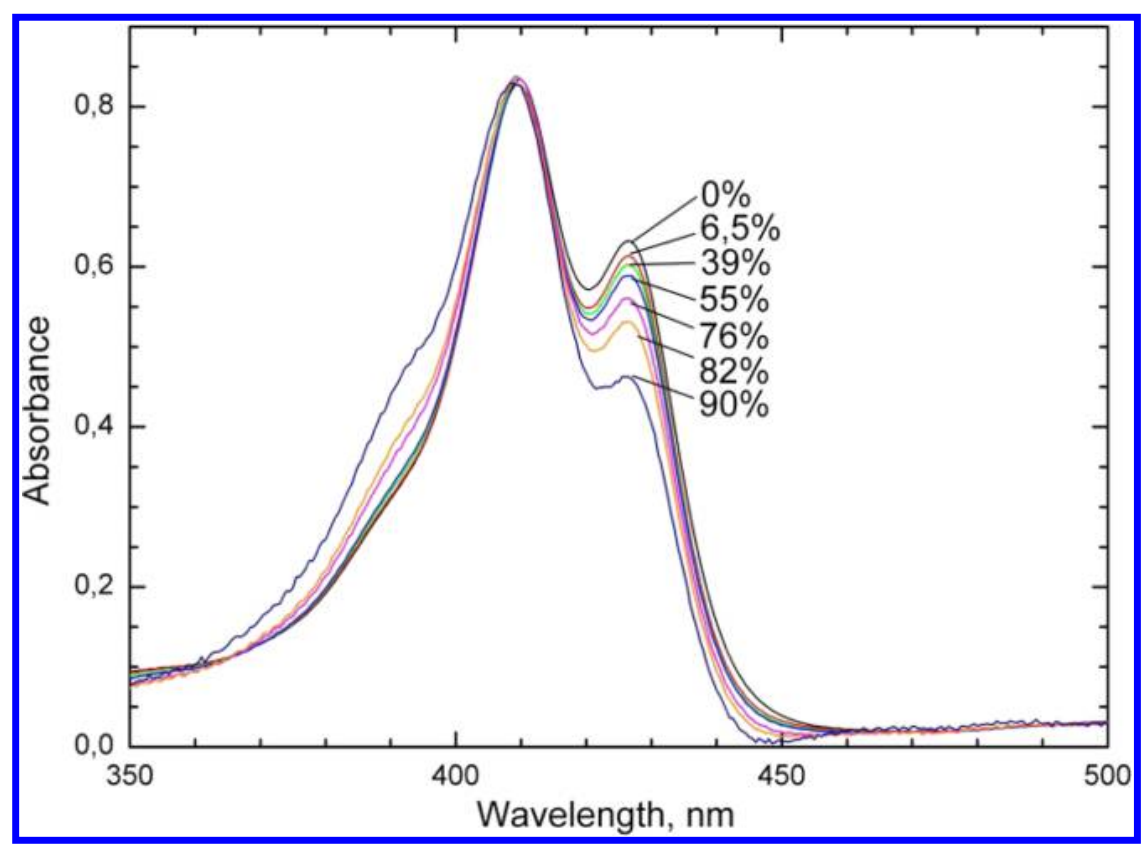

Figure 4. Ground state absorption spectra in the Soret region of the remaining Fb meso-pyrimidinylcorrole $\mathrm{H}_{3} \mathrm{AB}_{2}$ as a function of the percentage of protonation at $293 \mathrm{~K}$. Spectra are normalized for absorbance at $410 \mathrm{~nm}$ before titration.

pyrimidinylcorroles bearing one ( $\mathrm{AB}_{2}$-type), two ( $\mathrm{A}_{2} \mathrm{~B}$-type), and three $\left(\mathrm{A}_{3}\right.$-type $)$ pyrimidinyl groups ${ }^{12 \mathrm{a}, \mathrm{d}}$ indicated, however, that in all cases (i.e., either two protonation steps were observed at lower temperature or one protonation step was found at elevated temperatures), the absorption spectrum of the protonated product was the same, illustrating that the meso substituents are likely not involved in the observed acid-base equilibria. Such a behavior does not come as a real surprise since pristine pyrimidine is known to have a noticeably lower basicity $\left(\mathrm{p} K_{\mathrm{a}}=1.23\right)$ compared to pyridine $\left(\mathrm{p} K_{\mathrm{a}}=5.3\right) .{ }^{10 \mathrm{~d}}$ Thus, one can quite safely conclude that the same protonated $\mathrm{H}_{4} \mathrm{AB}_{2}{ }^{+}$corrole molecules seem to form with two different rates, i.e., the two $\mathrm{NH}$ tautomers have different basicity.

Having formed a single protonation product without any intermediate species, the two distinct rates in the protonation kinetics can arise from heterogeneity of the initial $\mathrm{Fb}$ molecules. The possible contribution of dimer formation to the observed absorbance changes can be excluded since the corrole concentrations were well below the aggregation limit (as pointed out in the experimental section). Therefore, the individual protonation of $\mathrm{NH}$ tautomers of corrole $\mathrm{H}_{3} \mathrm{AB}_{2}$ seems to be the only plausible explanation. If this assumption is valid, the proportion of the two $\mathrm{NH}$ tautomer concentrations will vary during the course of the protonation as the contribution from the quickly reacting $\mathrm{NH}$ tautomer should decrease faster. The absorption spectrum of the nonprotonated species $A(\lambda)\left[\mathrm{H}_{3} \mathrm{AB}_{2}\right]$ can be calculated at every concentration of added acid, i.e., at each point during the course of the titration. To obtain such a spectrum, the spectrum of monoprotonated molecules, scaled to the percentage of protonation $p$ at a given acid concentration, $p A(\lambda)\left[\mathrm{H}_{4} \mathrm{AB}_{2}{ }^{+}\right]$, should be subtracted from the total absorption spectrum $A_{\lambda}$ measured at a given acid concentration. The percentage of protonation can easily be calculated due to the small overlap of the long-wavelength absorption bands of the $\mathrm{Fb}$ corrole and its monoprotonated counterpart in the spectral range above 640 $\mathrm{nm}$. The $p$ value is equal to the ratio $A\left(\lambda_{\mathrm{i}}\right)\left[\mathrm{H}_{4} \mathrm{AB}_{2}{ }^{+}\right] /$ $A\left(\lambda_{\mathrm{i}}\right)_{\mathrm{F}}\left[\mathrm{H}_{4} \mathrm{AB}_{2}{ }^{+}\right]$taken at any wavelength $\lambda_{\mathrm{i}}$ in the range above $640 \mathrm{~nm}$, where the $\mathrm{Fb}$ corrole molecules do not absorb noticeably. $A\left(\lambda_{\mathrm{i}}\right)_{\mathrm{F}}\left[\mathrm{H}_{4} \mathrm{AB}_{2}^{+}\right]$denotes the finally measured spectrum when all $\mathrm{Fb}$ molecules in solution are converted into monoprotonated ones. The small absorbance in this spectral range due to the long wavelength tail of the pure electronic $\mathrm{Q}(0-0)$ band of the $\mathrm{Fb}$ corrole can be neglected since the extinction coefficient at the maximum $(644 \mathrm{~nm})$ of the $\mathrm{Q}(0-0)$ band of the monoprotonated corrole exceeds the extinction coefficient of the $\mathrm{Fb}$ corrole at the same wavelength by 25 times.

The calculated absorption spectra for nonprotonated species $A(\lambda)\left[\mathrm{H}_{3} \mathrm{AB}_{2}\right]$ at different percentages of protonation in the Soret band region are displayed in Figure 4. Indeed, changes in the absorption spectra of the nonprotonated species were observed during the course of protonation. The absorbance ratio of the two peaks in the Soret band region $A(427) / A(410)$ tends to decrease with increasing percentage of protonation. Therefore, one can state that our suggestion on the heterogeneity of $\mathrm{Fb}$ corroles due to coexistence of two $\mathrm{NH}$ tautomers is supported by the obtained absorption spectra at different protonation steps. Thus, the long wavelength tautomer T1 assigned to the Soret band at $427 \mathrm{~nm}$ seems to be the quickly reacting one since, in solutions with a high percentage of protonated molecules, its contribution to the total absorbance decreases markedly. On the contrary, the short wavelength tautomer T2 peaking at $410 \mathrm{~nm}$ has a much slower protonation rate. At the very end of the titration, it should dominate in the absorbance of nonprotonated molecules.

Thus, the solution during the course of the titration should be considered as consisting of three species, instead of a binary system, due to the presence of two $\mathrm{Fb}$ corrole $\mathrm{NH}$ tautomers and the protonated species. In general, when two processes take place in solution simultaneously, the isosbestic points should change. However, as we have already stated above, the isosbestic points in the absorption spectra do not move during the course of the titration. This apparent contradiction needs to be explained. The spectra presented in Figure 4 indicate that the absorbance of each of the two $\mathrm{NH}$ tautomers is accidentally 
Scheme 2. Equilibria between the Corrole Species in Solution upon Protonation

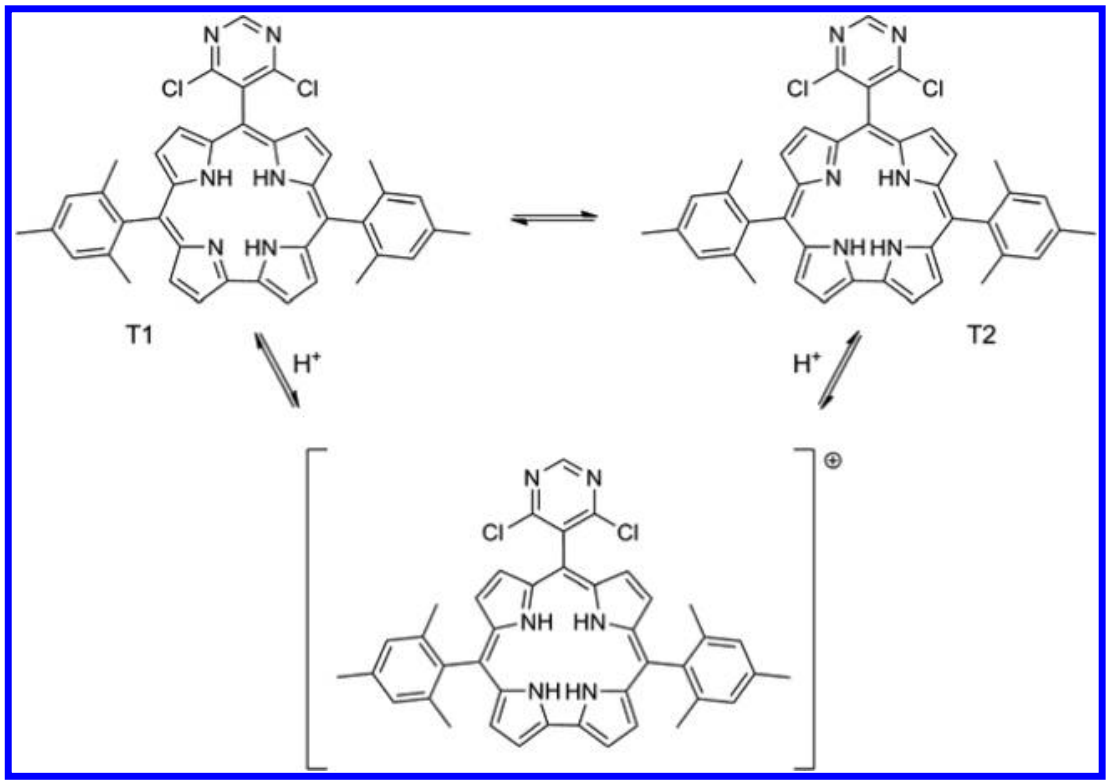

the same (within experimental uncertainty) in the spectral regions where the isosbestic points for the transition from $\mathrm{Fb}$ to monoprotonated species are found (see above and compare Figures 2 and 4). Therefore, mutual exchange between the two $\mathrm{NH}$ tautomers cannot afford an additional contribution to the absorbance. Spectral changes observed are due to the formation of protonated species, and the same set of isosbestic points is observed during the course of the whole titration procedure as a result. Additionally, we should underline here that there is no complete conversion between the corrole $\mathrm{NH}$ tautomers, but only a change in the population ratio. This is due to the fact that a more complicated scheme of mutual equilibria of three species arises if the protonation occurs in addition to $\mathrm{NH}$ tautomerization (Scheme 2). One can see that, in such a case, six processes are involved in the equilibrium between the two $\mathrm{NH}$ tautomers instead of two as it is the case without the addition of acid.

The possibility of exchange between the corrole $\mathrm{NH}$ tautomers and the relationship of the probabilities of $\mathrm{T} 1 \rightarrow$ $\mathrm{T} 2$ and $\mathrm{T} 2 \rightarrow \mathrm{T} 1$ tautomerization with those for protonation of the $\mathrm{T} 1$ and $\mathrm{T} 2$ tautomers seem to be the key features of the case under consideration. As the first limit, let us assume that both probabilities $\mathrm{T} 1 \rightarrow \mathrm{T} 2$ and $\mathrm{T} 2 \rightarrow \mathrm{T} 1$ are identical and equal to zero, i.e., $\mathrm{NH}$ tautomerization is frozen. Having both $\mathrm{NH}$ tautomers in observable concentrations, the protonation of each of them occurs independently. A plot of the amount of protonated species as a function of the acid concentration would reveal two distinct steps in case the protonation rates are different. The larger the difference in the protonation rates of the $\mathrm{NH}$ tautomers, the larger the difference in the slope of the two steps on the plot. The second limit occurs when $\mathrm{NH}$ tautomerization is much faster than the protonation rate. The overall protonation reaction will be limited by the protonation rate. Therefore, formation of the protonated species is preferred to occur with the quickly reacting $\mathrm{NH}$ tautomer or, in terms of the reaction kinetics, within one step. The slope of the dependence should be that of the quickly reacting $\mathrm{NH}$ tautomer in this limiting case.

The time scale and rates of the processes involved can be roughly estimated by means of comparison with the well- studied phenomenon of quenching of excited states by molecular oxygen. ${ }^{27}$ Thus, for the quenching of the fluorescence of porphyrins in most organic solvents, the diffusion-controlled bimolecular rate constant is of the order of $1 \times 10^{10}(\mathrm{M} \cdot \mathrm{s})^{-1} \cdot{ }^{28}$ When the monomolecular (i.e., without quenching by oxygen) fluorescence lifetime is of the order of 1 ns, the quenching efficiency is negligibly small, i.e., molecules can deactivate without interaction with oxygen. The published data for the studied pyrimidinylcorrole ${ }^{12 \mathrm{c}}$ indicate that its fluorescence lifetime is about $2.5 \mathrm{~ns}$, and bands belonging to both corrole $\mathrm{NH}$ tautomers are observed in the fluorescence spectra. Therefore, one can suggest that the corrole finds itself in one or another tautomeric form for at least a few nanoseconds. Then, on the basis of the average value of the proton diffusion coefficient $D_{\mathrm{H}+}=1 \times 10^{-4} \mathrm{~cm}^{2} \cdot \mathrm{s}^{-1}$ in solvents with viscosity of $\sim 1 \mathrm{mPa} \cdot \mathrm{s}$ at $300 \mathrm{~K}$ and assuming the interaction radius $R$ for protonation to be equal to the distance from the macrocycle center to the meso-carbon position ( 0.34 $\mathrm{nm}$ ), the diffusion-controlled protonation rate constant can be calculated with Smolukhovsky's equation $k_{\mathrm{D}}=(4 \pi / 1000)$ $D_{\mathrm{H}+} N_{\mathrm{A}} R$. Such estimation gives a $k_{\mathrm{D}}$ value of $0.65 \times 10^{10}$ $(\mathrm{M} \cdot \mathrm{s})^{-1}$. Thus, one can conclude that the processes we deal with in this work happen on the nanosecond time-scale, as is observed for fluorescence quenching by molecular oxygen. It is likely that this nanosecond time domain lies at the critical point between the two cases of corrole protonation described above. Therefore, a very precise tuning of the reaction conditions by means of a rather small increase in temperature allows to switch protonation to another regime. It is important to stress again that both the corrole $\mathrm{NH}$ tautomerization rate and the diffusion-controlled protonation reaction are temperature dependent. Therefore, the change we observe for the protonation process results from a complex function of temperature with several independent parameters involved. A more detailed mechanism of the temperature dependence of the protonation of corroles deserves and requires a separate indepth study.

However, more insight into the problem can already be achieved by consideration of a phenomenological theoretical model describing the system. ${ }^{29}$ The case we deal with seems to 


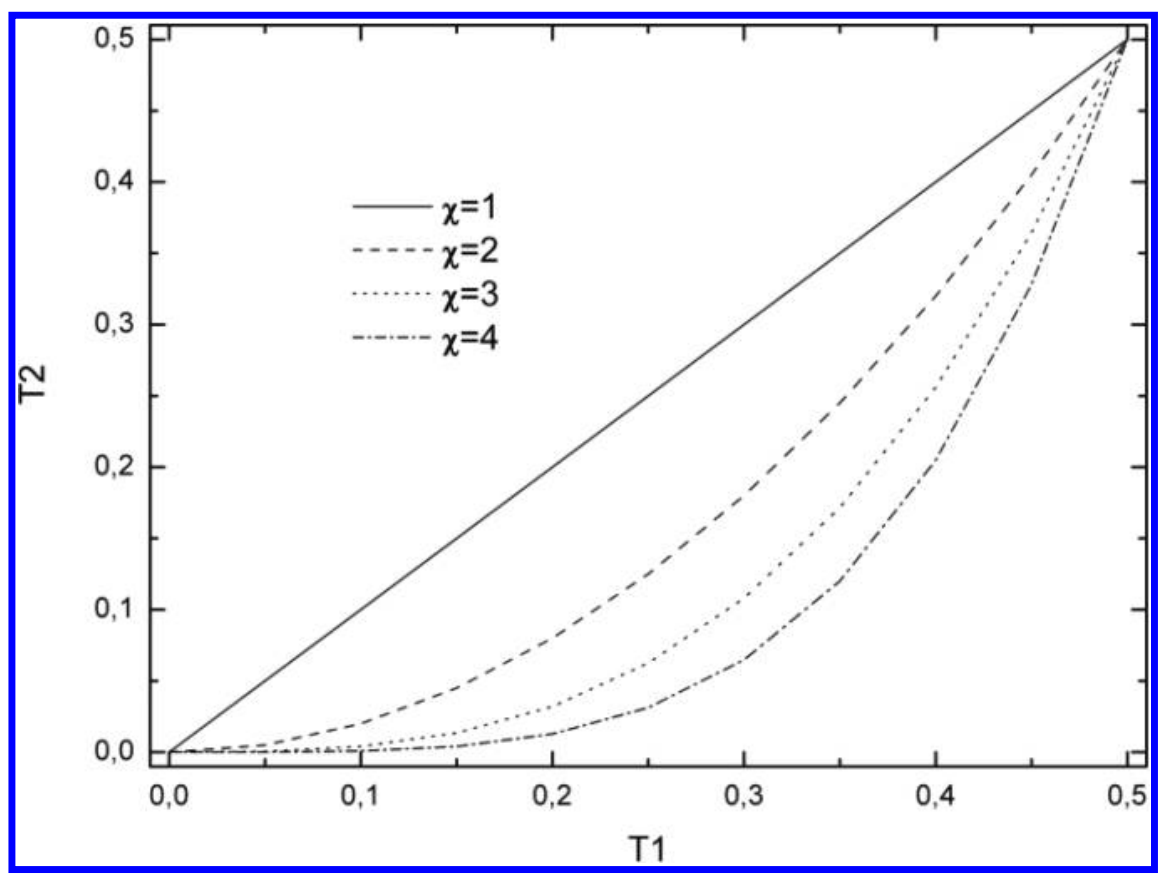

Figure 5. Relationship between the concentration of the T1 and T2 corrole tautomers during the course of protonation at different $\chi$ values, calculated with eqs 7.1-7.2. Equal initial concentrations are assumed: $\mathrm{T} 1_{0}=\mathrm{T} 2_{0}=0.5$.

be close to the first limiting case, i.e., the exchange rate between the $\mathrm{T} 1$ and $\mathrm{T} 2$ tautomers is much slower as compared to the protonation rate at $298 \mathrm{~K}$. The narrow $\mathrm{pH}$ range for protonation and the steepness of the protonation curve allow us to suggest that dissociation of the protonated corrole can be neglected. Therefore, protonation will be considered as an irreversible process. In such a case, the theoretical considerations can be simplified. In this approximation, the system is represented by two noninteracting tautomers $\mathrm{T} 1$ and $\mathrm{T} 2$, whose populations before the titration procedure are due to thermal equilibrium, as was shown above (Figure 1, inset). Thus, the $\mathrm{NH}$ tautomer populations before titration (at $t_{0}$ ) are subject to the rule

$$
\mathrm{T} 1_{0}=1 /(1+\alpha), \quad \mathrm{T} 2_{0}=\alpha /(1+\alpha)
$$

where $0 \leq \alpha \leq 1$, depending on the temperature and energy barriers for tautomerization.

The system of differential equations for the stationary $\mathrm{NH}$ tautomer concentrations $\mathrm{T} 1$ and $\mathrm{T} 2$ in dimensionless form is the following:

$$
\begin{aligned}
& \frac{\mathrm{dT} 1}{\mathrm{~d} \tau}=-\chi \mathrm{T} 1 D \\
& \frac{\mathrm{dT} 2}{\mathrm{~d} \tau}=-\mathrm{T} 2 D \\
& \frac{\mathrm{d} D}{\mathrm{~d} \tau}=-\chi \mathrm{T} 1 D-\mathrm{T} 2 D \\
& \frac{\mathrm{d} C}{\mathrm{~d} \tau}=\chi \mathrm{T} 1 D+\mathrm{T} 2 D
\end{aligned}
$$

where $\mathrm{T} 1, \mathrm{~T} 2, C$, and $D$ are dimensionless normalized concentrations of $\mathrm{Fb}$ corrole $\mathrm{NH}$ tautomers and monoprotonated corrole and acid, respectively, and $\chi$ is the ratio of the protonation constants for tautomers $\mathrm{T} 1$ to $\mathrm{T} 2$. From these equations, the following relationships can be derived:

$$
\begin{aligned}
& \frac{\mathrm{d}}{\mathrm{d} \tau}(\mathrm{T} 1+\mathrm{T} 2+C) \equiv 0 \\
& \frac{\mathrm{d}}{\mathrm{d} \tau}(D+C) \equiv 0 \\
& \frac{\mathrm{d}}{\mathrm{d} \tau}(\mathrm{T} 1+\mathrm{T} 2-D) \equiv 0
\end{aligned}
$$

This gives

$$
\begin{aligned}
& \mathrm{T} 1+\mathrm{T} 2+C=1 \\
& D+C=\beta \\
& \mathrm{T} 1+\mathrm{T} 2-D=1-\beta
\end{aligned}
$$

where $\beta$ is the quantity of acid added to solution at a given protonation step. Relationships 6.1-6.3 are valid for both dynamic and stationary regimes. From eqs 4.1 and 4.2, after integration, one can obtain, that

$$
\frac{\mathrm{T} 1}{\mathrm{~T} 1_{0}}=\left(\frac{\mathrm{T} 2}{\mathrm{~T} 2_{0}}\right)^{\chi} \text { and } \frac{\mathrm{T} 2}{\mathrm{~T} 2_{0}}=\left(\frac{\mathrm{T} 1}{\mathrm{~T} 1_{0}}\right)^{1 / \chi}
$$

where the ratios $(\mathrm{T} 1) /\left(\mathrm{T} 1_{0}\right)$ and $(\mathrm{T} 2) /\left(\mathrm{T} 2_{0}\right)$ represent the residual ratios of tautomers $\mathrm{T} 1$ and $\mathrm{T} 2$ at each protonation step. One can see that, before the titration procedure, (T1)/ $\left(\mathrm{T} 1_{0}\right)=(\mathrm{T} 2) /\left(\mathrm{T} 2_{0}\right) \equiv 1$, and after complete conversion of $\mathrm{Fb}$ corrole in the monoprotonated form, $(\mathrm{T} 1) /\left(\mathrm{T} 1_{0}\right)=(\mathrm{T} 2) /$ $\left(\mathrm{T} 2_{0}\right) \equiv 0$. However, the ratios $(\mathrm{T} 1) /\left(\mathrm{T} 1_{0}\right)$ and $(\mathrm{T} 2) /\left(\mathrm{T} 2_{0}\right)$ have different dependencies on the expended acid quantity $\beta$. This is a consequence of the nonlinear character of the system of eqs 4.1-4.4. This means that tautomers $\mathrm{T} 1$ and $\mathrm{T} 2$ coexist during the whole titration procedure, as one can see from Figure 4, and both of them disappear at the same final protonation step. However, the proportion of concentrations of $\mathrm{T} 1$ and $\mathrm{T} 2$ tautomers will vary during the protonation procedure, with the difference being larger when $\chi$ is higher (Figure 5). 


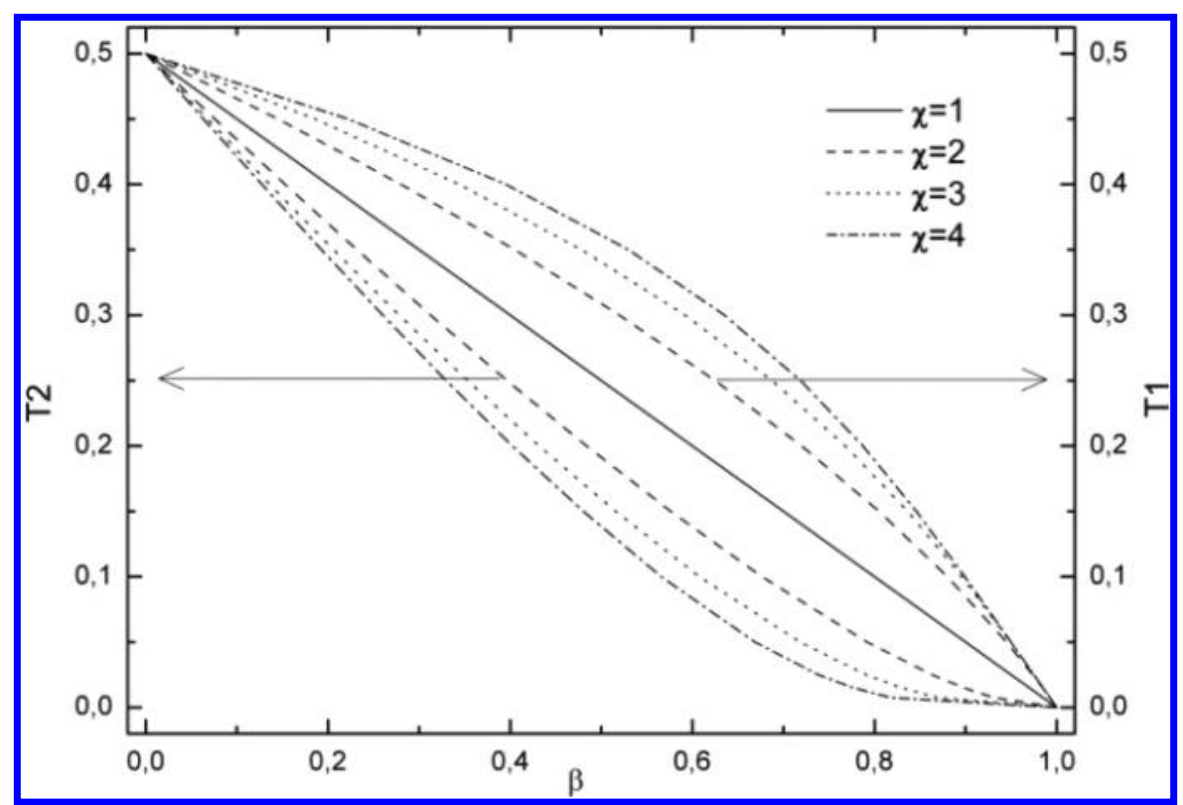

Figure 6. Concentration of $\mathrm{T} 1$ and $\mathrm{T} 2$ tautomers as a function of the expended acid $\beta$ at different $\chi$ values calculated with eqs 9.1 and 9.2. Equal initial concentrations are assumed: $\mathrm{T} 1_{0}=\mathrm{T} 2_{0}=0.5$.

From system $6.1-6.3$, the next relationships are derived for 0 $\leq \beta \leq 1$ :

$$
\begin{aligned}
& \mathrm{T} 1+\mathrm{T} 2=1-\beta \\
& C=1-(\mathrm{T} 1+\mathrm{T} 2)=\beta \\
& D=\beta-C=0
\end{aligned}
$$

One can see that the sums of the concentrations of $\mathrm{Fb}$ tautomers $\mathrm{T} 1+\mathrm{T} 2$ and the concentration of monoprotonated species $C$ are linear functions of the expended acid $\beta$. Thus, neither of these dependencies can be used for direct determination of the amount of reacting species in solution. However, the signal we measure in the titration experiments is proportional to the absorbance changes of both initial species (i.e., $\mathrm{NH}$ tautomers $\mathrm{T} 1$ and $\mathrm{T} 2$ ) and the monoprotonated corrole. At a given wavelength $\lambda$, each of these species has its own extinction coefficient $\varepsilon_{\mathrm{i}}(\lambda)$. The expression for the spectrophotometrical signal is proportional to the sum $S(\lambda)$ $\approx \varepsilon_{\mathrm{T} 1}(\lambda) \mathrm{T} 1+\varepsilon_{\mathrm{T} 2}(\lambda) \mathrm{T} 2+\varepsilon_{\mathrm{C}}(\lambda) C$. Therefore, the experiment is able to reveal the nonlinear character of the protonation, which results in the bend in the titration curve.

It is easy to obtain the parametrical equations for $\mathrm{T} 1$ as a function of $\beta$ and $\mathrm{T} 1_{0}$ or for $\mathrm{T} 2$ as a function of $\beta$ and $\mathrm{T} 2_{0}$ (or $\mathrm{T}_{1}$ ) for $0 \leq \beta \leq 1$. Thus, one can find by combining the eqs $7.1-7.2$ and 8.1:

$$
\begin{aligned}
\beta & =1-\mathrm{T} 1-\frac{1-\mathrm{T} 1_{0}}{\mathrm{~T} 1_{0}{ }^{1 / \chi}} \mathrm{T} 1^{1 / \chi} \\
\beta & =1-\mathrm{T} 2-\frac{\mathrm{T} 1_{0}}{\left(1-\mathrm{T} 1_{0}\right)^{\chi}} \mathrm{T} 2^{\chi} \\
& =1-\mathrm{T} 2-\frac{1-\mathrm{T} 2_{0}}{\mathrm{~T} 2_{0}{ }^{\chi}} \mathrm{T} 2^{\chi}
\end{aligned}
$$

The functions 9.1 and 9.2 represent dependencies of concentration of either tautomer $\mathrm{T} 1$ or tautomer $\mathrm{T} 2$ on the expended acid $\beta$ and initial concentration $\left(\mathrm{T} 2_{0}\right.$ or $\left.\mathrm{T} 1_{0}\right)$ in implicit form. One can use it to prepare the corresponding plots (Figure 6).

The shape of the titration curve depends on the initial conditions. The temperature is one of the factors that strongly influence these conditions. Temperature is known to be a major factor to change the probability of $\mathrm{NH}$ tautomerization in tetrapyrrolic compounds. ${ }^{5,30}$ Temperature-dependent NMR measurements revealed that $\mathrm{NH}$ tautomerization for a series of triaryl-substituted corroles does not occur at temperatures around $200 \mathrm{~K}$ (on the NMR time scale), but a minor increase in temperature leads to a fast increase in the tautomerization rate. $^{30}$ Therefore, the ratio of quickly reacting to slowly reacting $\mathrm{NH}$ tautomers, which undergo protonation, would increase dramatically with temperature since the former becomes a trap with respect to the slowly reacting one due to the much higher probability of protonation of the quickly reacting $\mathrm{NH}$ tautomer.

Therefore, titrations at elevated temperatures can be suggested to testify the proposed model. If the proposed model is valid, the increase in the $\mathrm{NH}$ tautomerization rate with temperature would ultimately lead to a change of the titration curve for protonation. Indeed, an increase in temperature to $308 \mathrm{~K}$ led to dramatic changes in the protonation titration curve: only one step was revealed. The same situation was found at $318 \mathrm{~K}$ as well. Absorption spectra measured during the protonation at $318 \mathrm{~K}$ along with the corresponding titration curve are presented in Figure 7 . The values of the protonation constant $K_{\mathrm{b}}$ were measured to be 151 and 145 at 308 and 318 $\mathrm{K}$, respectively. These values are equal, within experimental uncertainty, to the protonation constant $K_{\mathrm{b} 2}=151$ determined for the quickly reacting $\mathrm{NH}$ tautomer at $298 \mathrm{~K}$. Indeed, preferential protonation takes place for the quickly reacting tautomer at elevated temperatures in both cases. Therefore, one can state that the protonation of individual corrole tautomers is indeed observed at temperatures in the range of 293-298 K.

Individual $\mathrm{NH}$ tautomers apparently can be distinguished by their protonation constants, which differ by approximately a factor of 3.5 in the case of meso-pyrimidinylcorrole $\mathrm{H}_{3} \mathrm{AB}_{2}$. This difference seems to have both an electronic and structural origin. Because of the asymmetry of the corrole macrocycle, the 


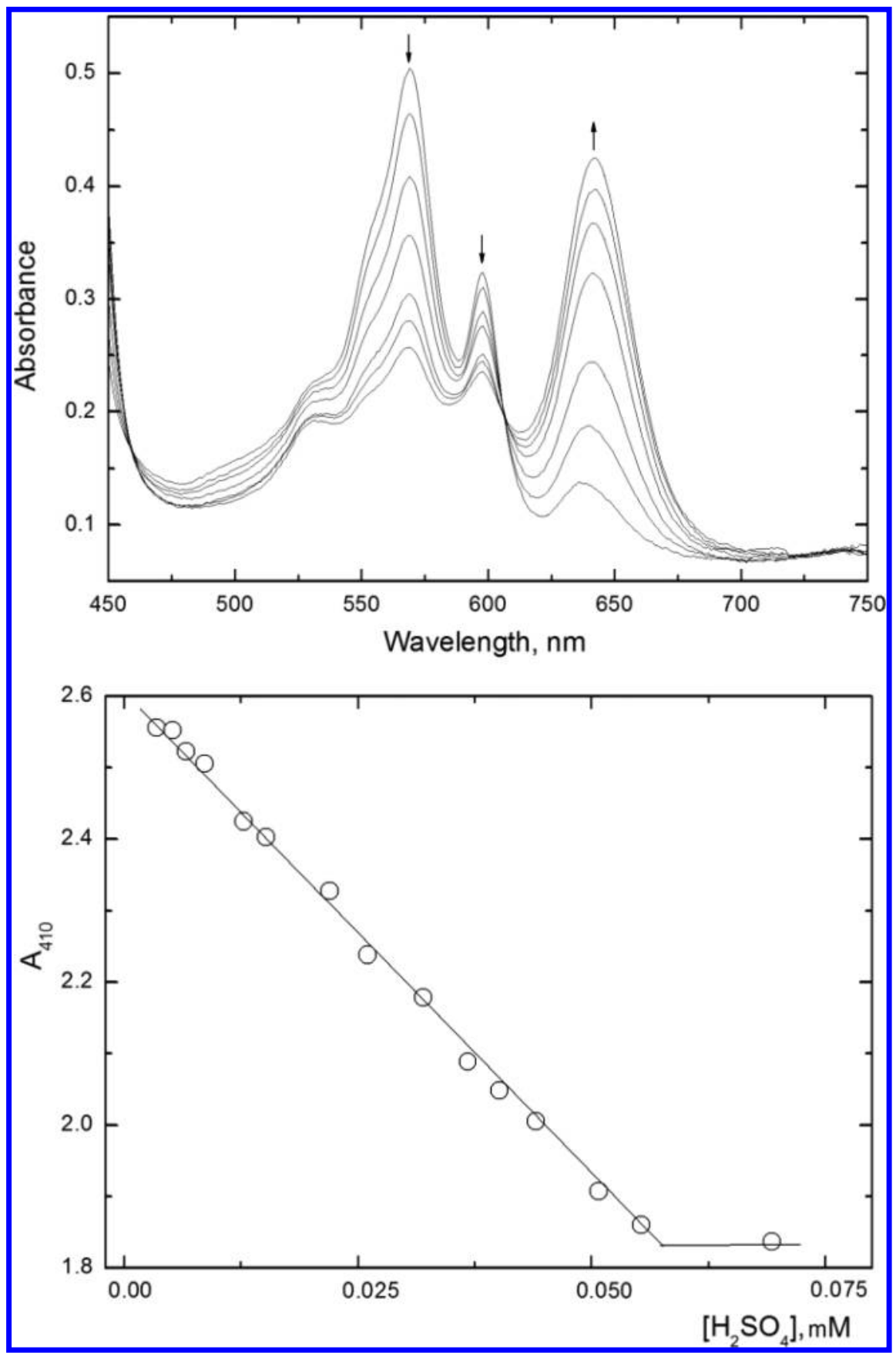

Figure 7. Changes in the ground state absorption spectra in the $\mathrm{Q}$ bands region upon protonation of $\mathrm{Fb}$ meso-pyrimidinylcorrole $\mathrm{H}_{3} \mathrm{AB}_{2}(C=9.9 \times$ $10^{-6} \mathrm{M}$ ) at $318 \mathrm{~K}$ (top). Corresponding titration curve at $\lambda=410 \mathrm{~nm}$ (bottom).

two NH tautomers have different electronic structures, which can clearly be seen in their absorption spectra. Thus, the splitting between the Soret band maxima for the T1 and T2 tautomers is about $970 \mathrm{~cm}^{-1}$. Such a large splitting value undoubtedly results from a difference in the electronic density distribution in the macrocycle. However, in accordance with published X-ray data, the corrole macrocycle undergoes substantial nonplanar distortions due to steric hindrance of three hydrogen atoms in the macrocyclic core. ${ }^{8 \mathrm{a}, 31}$ Formation of nonplanar conformers in the case of mono- and diprotonated porphyrins has been known for a long time. ${ }^{20}$ The degree of distortion in the case of corroles can be even higher since the macrocyclic core is smaller compared to that of porphyrins. Moreover, depending on which of the two tautomers is being formed, the distortion pattern was found to be different. ${ }^{8 a}$ Analysis of X-ray data showed that the hydrogen-free pyrrolenine ring (i.e., the ring to be protonated) lies in about the mean corrole plane in both cases, whereas the tilting angles for the neighboring pyrrole rings differ for about $9^{\circ}$ for the two $\mathrm{NH}$ tautomers. These structural differences for the two $\mathrm{NH}$ tautomers at the site next to the hydrogen-free nitrogen atom are likely to account for the differences in the protonation rates as well.

In the above discussion, we have reported on the results obtained in EtOH solution. However, ethanol does not bring any exclusivity to the acid-base equilibria observed. Exactly the same behavior was found upon titration of meso-pyrimidinylcorrole $\mathrm{H}_{3} \mathrm{AB}_{2}$ in 2-Me-THF. At the same time, we should 
point out that the solvent dependence of the (pyrimidinyl)corrole spectra is quite strong. The source of this pronounced solvent dependence was found to be the high acidity of the corrole, enabling its deprotonated form to be easily stabilized in several solvents. ${ }^{32}$ As a result, $\mathrm{Fb}$, fully deprotonated or $\mathrm{Fb}$ deprotonated species mixtures of different proportions can be found depending on the solvent. However, when the $\mathrm{Fb}$ was the starting species in the titration studies, no difference in the protonation behavior was observed as compared to the case described above for EtOH. When the titration started from the deprotonated species (e.g., in $\mathrm{MeCN}$ ), an additional (very fast) step led to the formation of the $\mathrm{Fb}$ species, and then, the protonation proceeded in the same manner as reported above.

The number of corrole derivatives for which titration studies have been carried out to date is very limited. ${ }^{9 c, 10}$ mesoPyrimidinylcorroles are most probably not the only group of corroles able to reveal individual protonation of $\mathrm{NH}$ tautomers. A number of parameters are involved here; the substitution pattern, solution properties (viscosity and polarity of the solvent; type of acid chosen for the titration), and temperature. The $\mathrm{AB}_{2}$-meso-pyrimidinylcorrole studied in this article seems to be simply the first one for which the appropriate conditions have been achieved, thus allowing a favorable relationship between the $\mathrm{NH}$ tautomerization and the protonation rates. In our opinion, due to their electronic properties, pyrimidinyl substituents might be able to slow down the rate of the $\mathrm{NH}$ tautomerization, as compared to other studied corrole derivatives, thus facilitating observation of individual tautomer protonation. To elucidate all the peculiarities of the influence of the pyrimidinyl substituent on the formation of monoprotonated species, additional experiments should be performed, which are currently carried out within our laboratories. Inspired by the findings presented in this article, detailed studies of the optical properties of both ground and excited states for individual $\mathrm{NH}$ tautomers and the influence of the coexistence of two tautomer species on the formation of the spectral signatures of corroles in solution have been conducted as well. These results will be published in the companion articles. ${ }^{25,32}$

\section{CONCLUSIONS}

In this article, we have investigated the protonation of a freebase meso-pyrimidinyl-substituted $\mathrm{AB}_{2}$-corrole in ethanol solution by stepwise addition of sulfuric acid (via UV-vis absorption studies), with the aim to estimate its basicity and potential anion binding features. During this study, it was noticed that the contribution of the two corrole $\mathrm{NH}$ tautomers to the general protonation mechanism could be visualized, depending on the temperature at which the protonation experiment was conducted. To the best of our knowledge, this is the first well-illustrated spectrophotometric observation of individual properties of corrole $\mathrm{NH}$ tautomers. Evidences for the contribution of both tautomers as well as their optical features are discussed based on spectroscopic results and simulation data. ${ }^{33}$

By this study, a few pending issues/controversies in the corrole (spectroscopy) field, the ongoing debate on the possible contribution of corrole $\mathrm{NH}$ tautomers to their spectroscopic signatures ${ }^{8}$ and hypotheses on the reason of the Soret band splitting for free-base corroles, ${ }^{10 a, 12 c, 22,23}$ have been clarified to a large extent. The obtained results are hence estimated to be of significant importance to improve the understanding of structure-property relationships in mesosubstituted corroles.

\section{AUTHOR INFORMATION}

\section{Corresponding Author}

*(W.M.) Tel: (+32) 11 268312. Fax: (+32) 11 268299. E-mail: wouter.maes@uhasselt.be. (M.M.K.) Tel: (+375) 172841563. Fax: (+375) 17284 0679. E-mail: kruk@imaph.bas-net.by.

\section{Author Contributions}

The manuscript was written through contributions of all authors. All authors have given approval to the final version of the manuscript.

\section{Notes}

The authors declare no competing financial interest.

\section{ACKNOWLEDGMENTS}

This work has been carried out with partial financial support from FP-7 project DphotoD-PEOPLE-IRSES-GA-2009247260. The State Program of Scientific Research "Convergence" of the Republic of Belarus (projects 3.1.03 and 3.4.01) is acknowledged by M.M.K., A.S.S., and V.A.S. W.M., T.H.N., and W.D. thank the FWO (Fund for Scientific Research, Flanders), the KU Leuven, and the Ministerie voor Wetenschapsbeleid for continuing financial support. T.H.N. further acknowledges the IWT (Institute for the Promotion of Innovation through Science and Technology in Flanders) and the Alexander von Humboldt Foundation for a doctoral and postdoctoral fellowship, respectively.

\section{REFERENCES}

(1) Reviews on (synthetic) corrole chemistry: (a) Gryko, D. T. Eur. J. Org. Chem. 2002, 1735-1743. (b) Gryko, D. T.; Fox, J. P.; Goldberg, P. J. Porphyrins Phthalocyanines 2004, 8, 1091-1105. (c) Ghosh, A. Angew. Chem., Int. Ed. 2004, 43, 1918-1931. (d) Nardis, S.; Monti, D.; Paolesse, R. Mini-Rev. Org. Chem. 2005, 2, 355-374. (e) Paolesse, R. Synlett 2008, 2215-2230. (f) Gryko, D. T. J. Porphyrins Phthalocyanines 2008, 12, 906-917. (g) Lemon, C. M.; Brothers, P. J. J. Porphyrins Phthalocyanines 2011, 15, 809-834.

(2) (a) Andrioletti, B.; Rose, E. J. Chem. Soc., Perkin. Trans. 1 2002, 715-716. (b) Collman, J. P.; Decréau, A. Org. Lett. 2005, 7, 975-978. (c) Koszarna, B.; Gryko, D. T. J. Org. Chem. 2006, 71, 3707-3717. (d) Bröring, M.; Milsmann, C.; Ruck, S.; Köhler, S. J. Organomet. Chem. 2009, 694, 1011-1015. (e) Vale, L. S. H. P.; Barata, J. F. B.; Santos, C. I. M.; Neves, M. G. P. M. S.; Faustino, M. A. F.; Tomé, A. C.; Silva, A. M. S.; Paz, F. A. A.; Cavaleiro, J. A. S. J. Porphyrins Phthalocyanines 2009, 13, 358-368. (f) Hori, T.; Osuka, A. Eur. J. Org. Chem. 2010, 2379-2386. (g) Van Rossom, W.; Kundrat, O.; Ngo, T. H.; Lhotak, P.; Dehaen, W.; Maes, W. Tetrahedron Lett. 2010, 51, 2423-2426. (h) Zhan, H.-Y.; Liu, H.-Y.; Lu, J.; Wang, A.-Z.; You, L.L.; Wang, H.; Ji, L.-N.; Jiang, H.-F. J. Porphyrins Phthalocyanines 2010, 14, 150-157. (i) Mahammed, A.; Gross, Z. J. Porphyrins Phthalocyanines 2010, 14, 911-923. (j) Schöfberger, W.; Lengwin, F.; Reith, L. M.; List, M.; Knör, G. Inorg. Chem. Commun. 2010, 11871190. (k) Pittelkow, M.; Brock-Nannestad, T.; Bendix, J.; Christensen, J. B. Inorg. Chem. 2011, 50, 5867-5869. (1) Dogutan, D. K.; Stoian, S. A.; McGuire, R.; Schwalbe, M.; Teets, T. S.; Nocera, D. G. J. Am. Chem. Soc. 2011, 133, 131-140. (m) König, M.; Reith, L. M.; Monkowius, U.; Knör, G.; Bretterbauer, K.; Schoefberger, W. Tetrahedron 2011, 67, 4243-4252. (n) Pomarico, G.; Nardis, S.; Paolesse, R.; Ongayi, O. C.; Courtney, B. H.; Fronczek, F. R.; Vicente, M. G. H. J. Org. Chem. 2011, 76, 3765-3773. (o) Stefanelli, M.; Pomarico, G.; Tortora, L.; Nardis, S.; Fronczek, F. R.; McCandless, G. T.; Smith, K. M.; Manowong, M.; Fang, Y.; Chen, P.; Kadish, K. M.; Rosa, A.; Ricciardi, G.; Paolesse, R. Inorg. Chem. 2012, 51, 6928-6942.

(3) Reviews on corrole applications: (a) Aviv, I.; Gross, Z. Chem. Commun. 2007, 1987-1999. (b) Flamigni, L.; Gryko, D. T. Chem. Soc. Rev. 2009, 38, 1635-1646. (c) Aviv-Harel, I.; Gross, Z. Chem.-Eur. J. 
2009, 15, 8382-8394. (d) Aviv-Harel, I.; Gross, Z. Coord. Chem. Rev. 2011, 255, 717-736.

(4) (a) Barbe, J.-M.; Canard, G.; Brandès, S.; Guilard, R. Chem.-Eur. J. 2007, 13, 2118-2129. (b) Mahammed, A.; Gross, Z. Chem. Commun. 2010, 7040-7042. (c) Kupershmidt, L.; Okun, Z.; Amit, T.; Mandel, S.; Saltsman, I.; Mahammed, A.; Bar-Am, O.; Gross, Z.; Youdim, M. B. H. J. Neurochem. 2010, 113, 363-373. (d) Abu-Omar, M. M. Dalton Trans. 2011, 40, 3435-3444. (e) Suranjana Bose, S.; Pariyar, A.; Biswas, A. N.; Das, P.; Bandyopadhyay, P. Catal. Commun. 2011, 12, 446-449. (f) Dogutan, D. K.; McGuire, R.; Nocera, D. G. J. Am. Chem. Soc. 2011, 133, 9178-9180.

(5) (a) Storm, C. B.; Teklu, Y. J. Am. Chem. Soc. 1972, 94, 17451747. (b) Zenkevich, E. I.; Shulga, A. M.; Chernook, A. V.; Gurinovich, G. P. Chem. Phys. Lett. 1984, 109, 306-311.

(6) Ghosh, A.; Jynge, K. Chem.-Eur. J. 1997, 3, 823-833.

(7) Ghosh, A.; Almlöf, J. J. Phys. Chem. 1995, 99, 1073-1075.

(8) (a) Ding, T.; Harvey, J. D.; Ziegler, C. J. J. Porphyrins Phthalocyanines 2005, 9, 22-27. (b) Ding, T.; Aleman, E. A.; Modarelli, D. A.; Ziegler, C. J. J. Phys. Chem. A 2005, 109, 7411-7417.

(9) (a) Johnson, A. W.; Kay, I. T. J. Chem. Soc. 1965, 1620-1629. (b) Broadhurst, M. J.; Grigg, R.; Shelton, G.; Johnson, A. W. J. Chem. Soc., Perkin Trans. 1 1972, 143-151. (c) Mahammed, A.; Weaver, J. J.; Gray, H. B.; Abdelas, M.; Gross, Z. Tetrahedron Lett. 2003, 44, 20772079.

(10) (a) Shen, J.; Shao, J.; Ou, Z.; E, W.; Koszarna, B.; Gryko, D. T.; Kadish, K. M. Inorg. Chem. 2006, 45, 2251-2265. (b) Ou, Z.; Shen, J.; Shao, J.; E, W.; Galezowski, M.; Gryko, D. T.; Kadish, K. M. Inorg. Chem. 2007, 46, 2775-2786. (c) Shen, J.; Ou, Z.; Shao, J.; Galezowski, M.; Gryko, D. T.; Kadish, K. M. J. Porphyrins Phthalocyanines 2007, 11, 269-276. (d) Ou, Z.; Sun, H.; Zhu, W.; Da, Z.; Kadish, K. M. J. Porphyrins Phthalocyanines 2008, 12, 1-10.

(11) (a) Smeets, S.; Asokan, C. V.; Motmans, F.; Dehaen, W. J. Org. Chem. 2000, 65, 5882-5885. (b) Maes, W.; Dehaen, W. Synlett 2003, 79-82. (c) Maes, W.; Amabilino, D. B.; Dehaen, W. Tetrahedron 2003, 59, 3937-3943. (d) Maes, W.; Vanderhaeghen, J.; Dehaen, W. Chem. Commun. 2005, 2612-2614. (e) Maes, W.; Vanderhaeghen, J.; Smeets, S.; Asokan, C. V.; Van Renterghem, L. M.; Du Prez, F. E.; Smet, M.; Dehaen, W. J. Org. Chem. 2006, 71, 2987-2994. (f) Maes, W.; Dehaen, W. Pol. J. Chem. 2008, 82, 1145-1160. (g) Maes, W.; Dehaen, W. Eur. J. Org. Chem. 2009, 4719-4752.

(12) (a) Maes, W.; Ngo, T. H.; Vanderhaeghen, J.; Dehaen, W. Org. Lett. 2007, 9, 3165-3168. (b) Ngo, T. H.; Van Rossom, W.; Dehaen, W.; Maes, W. Org. Biomol. Chem. 2009, 7, 439-443. (c) Ngo, T. H.; Puntoriero, F.; Nastasi, F.; Robeyns, K.; Van Meervelt, L.; Campagna, S.; Dehaen, W.; Maes, W. Chem.-Eur. J. 2010, 16, 5691-5705. (d) Ngo, T. H.; Nastasi, F.; Puntoriero, F.; Campagna, S.; Dehaen, W.; Maes, W. J. Org. Chem. 2010, 75, 2127-2130. (e) Nastasi, F.; Campagna, S.; Ngo, T. H.; Dehaen, W.; Maes, W.; Kruk, M. Photochem. Photobiol. Sci. 2011, 10, 143-150. (f) Ngo, T. H.; Nastasi, F.; Puntoriero, F.; Campagna, S.; Dehaen, W.; Maes, W. Eur. J. Org. Chem. 2012, 28, 5605-5617.

(13) Dolman, D.; Stewart, R. Can. J. Chem. 1967, 45, 903-910.

(14) Gordon, A. J.; Ford, R. A. The Chemist's Companion. A Handbook of Practical Data, Techniques and References; Wiley-VCH: New York, 1972; p 231.

(15) Ivanova, Y. B.; Churakhina, Y. I.; Mamardashvili, N. Z. Russ. J. Gen. Chem. 2008, 78, 673-677.

(16) Our work does not bring the first observation of the individual features of $\mathrm{NH}$ tautomers in the optical spectra of tetrapyrrolic compounds at room temperature. There are two recently published reports where these observations have been made for dinuclear pyrrole-to-pyrrole bridged $\mathrm{Fb}$ phthalocyanines and for a series of $\mathrm{Fb}$ cycloketo-tetraphenylporphyrins: (a) Litwinski, C.; Corral, I.; Ermilov, E. A.; Tannert, S.; Fix, D.; Makarov, S.; Suvorova, O.; González, L.; Wöhrle, D.; Röder, B. J. Phys. Chem. B 2008, 112, 8466-8476. (b) Ermilov, E. A.; Büge, B.; Jasinski, S.; Jux, N.; Röder, B. J. Chem. Phys. 2009, 130, 134509 Our work extends these observations to corroles..
(17) Lenzer, T.; Ehlers, F.; Scholz, M.; Oswald, R.; Oum, K. Phys. Chem. Chem. Phys. 2010, 12, 8832-8839.

(18) Ghosh, A.; Wondimagegn, T.; Parusel, A. B. J. J. Am. Chem. Soc. 2000, 122, 5100-5104.

(19) (a) Gouterman, M.; Wagniere, G.; Snyder, L. R. J. Mol. Struct. 1963, 11, 108-127. (b) Gouterman, M. Optical Spectra and Electronic Structure of Porphyrins and Related Rings. In The Porphyrins; Dolphin, D., Ed.; Academic Press: New York, 1978; Vol. 3, pp 1-165.

(20) (a) Cheng, B.; Mungo, Q. Q.; Marques, H. M.; Scheidt, W. R. J. Am. Chem. Soc. 1997, 119, 10732-10742. (b) Rosa, A.; Ricciardi, G.; Baerends, E. J. J. Phys. Chem. A 2006, 110, 5180-5190. (c) De Luca, G.; Romeo, A.; Scolaro, L. M.; Ricciardi, G.; Rosa, A. Inorg. Chem. 2007, 46, 5979-5988.

(21) Ziegler, C. J.; Sabin, J. R.; Geier, G. R., III; Nemykin, V. N. Chem. Commun. 2012, 48, 4743-4745.

(22) Ventura, B.; Esposti, A. D.; Koszarna, B.; Gryko, D. T.; Flamigni, L. New. J. Chem. 2005, 29, 1559-1566.

(23) Koszarna, B.; Gryko, D. T. Chem. Commun. 2007, 2994-2996.

(24) (a) Quimby, D. J.; Longo, F. R. J. Am. Chem. Soc. 1975, 97, 5111-5117. (b) Sutter, T. P. G.; Rahimi, R.; Hambright, P.; Bommer, G. C.; Kumar, M.; Neta, P. J. Chem. Soc., Faraday Trans. 1993, 89, 495-502.

(25) Kruk, M. M.; Ngo, T. H.; Verstappen, P.; Starukhin, A. S.; Hofkens, J.; Dehaen, W.; Maes, W. J. Phys. Chem. A. 2012, DOI: $10.1021 /$ jp305326x, companion article.

(26) Ivanova, Y. B.; Sheinin, V. B.; Mamardashvili, N. Z. Russ. J. Gen. Chem. 2007, 77, 1561-1568.

(27) Schweitzer, C.; Schmidt, R. Chem. Rev. 2003, 103, 1685-1757.

(28) (a) Kruk, M. M. J. Appl. Spectrosc. 2006, 73, 686-693. (b) Kruk, M. M. J. Appl. Spectrosc. 2008, 75, 174-180.

(29) An extended version of this theoretical work, illustrating the application of the developed model on acid-base equilibria of corroles, will be the subject of an upcoming paper.

(30) Balazs, Y. S.; Saltsman, I.; Mahammed, A.; Tkachenko, E.; Golubkov, G.; Levine, J.; Gross, Z. Magn. Reson. Chem. 2004, 42, 624635.

(31) Gross, Z.; Galili, N.; Simkhovich, L.; Saltsman, I.; Botoshansky, M.; Blaeser, D.; Boese, R.; Goldberg, I. Org. Lett. 1999, 1, 599-602.

(32) Kruk, M. M.; Ngo, T. H.; Savva, V. A.; Starukhin, A. S.; Dehaen, W.; Maes, W. J. Phys. Chem. A. 2012, DOI: 10.1021/jp305327c, companion article.

(33) In principle, a different interpretation of the ground state absorption spectrum of the tautomeric mixture, related to the orbital origin for the two (strongest) observed bands in the Soret region, cannot fully be excluded for now, but all results gathered so far support our assignment. As for the main results reported in this article, they would remain valid independently of the exact (detailed) interpretation of the strongly overlapped Soret absorbance resulting from the spectra of two corrole $\mathrm{NH}$ tautomers. Coexistence of the two $\mathrm{NH}$ tautomers gives rise to a change in the proportion between the tautomers with temperature and their different basicity results in the complex shape of the titration curve measured upon formation of the protonated corrole. 